\title{
EGFR and gastrointestinal stromal tumor: an immunohistochemical and FISH study of 82 cases
}

\author{
Lisandro F Lopes and Carlos E Bacchi \\ Consultoria em Patologia, Botucatu, Sao Paulo, Brazil
}

\begin{abstract}
Gastrointestinal stromal tumor is the most common mesenchymal neoplasm of the gastrointestinal tract. Mutually exclusive $K I T$ or platelet-derived growth factor receptor- $\alpha$ mutations are key events in gastrointestinal stromal tumor pathogenesis, and specific treatment targeting KIT/platelet-derived growth factor receptor- $\alpha$ activation is available. Epidermal growth factor receptor plays an important role in cancer biology and also constitutes a promising molecular target of therapy. Very few reports have been published in the literature about the relationship between gastrointestinal stromal tumor and epidermal growth factor receptor. The aim of this study was to investigate epidermal growth factor receptor immunohistochemical expression and epidermal growth factor receptor gene amplification in $\mathbf{8 2}$ consecutive gastrointestinal stromal tumor cases using tissue microarray technique. Hematoxylin- and eosin-stained sections and clinical information were reviewed, and expression of CD117 (KIT), CD34 and epidermal growth factor receptor was investigated by immunohistochemistry. Epidermal growth factor receptor gene copy number was determined using fluorescence in situ hybridization. Immunohistochemistry revealed that CD117 and CD34 were expressed in 96 and $57 \%$ of tumors, respectively. Variable epidermal growth factor receptor protein immunohistochemical overexpression was detected in $96 \%$ of gastrointestinal stromal tumor cases, but none of the 75 cases with represented tumor tissue cores and countable fluorescence signals exhibited epidermal growth factor receptor gene amplification by fluorescence in situ hybridization. These results show that there is no correlation between epidermal growth factor receptor protein overexpression by immunohistochemistry and epidermal growth factor receptor gene amplification by fluorescence in situ hybridization. Considering that the mechanisms of epidermal growth factor receptor protein overexpression are not well understood and the possibility that anti-epidermal growth factor receptor therapy may be beneficial for patients with gastrointestinal stromal tumor that overexpresses epidermal growth factor receptor, additional studies are encouraged.
\end{abstract}

Modern Pathology (2007) 20, 990-994; doi:10.1038/modpathol.3800932; published online 20 July 2007

Keywords: epidermal growth factor receptor; fluorescence in situ hybridization; gastrointestinal stromal tumor; immunohistochemistry; KIT; tissue microarray

Gastrointestinal stromal tumor (GIST) is the most common mesenchymal neoplasm of the gastrointestinal (GI) tract. GIST generally occurs in older individuals (over the age of 50) and it can arise anywhere along the GI tract or even outside of it (extra-GI GIST), as in mesentery, omentum, retroperitoneum and pelvis. GISTs show peculiar immunohistochemical (KIT or CD117 and CD34 positivity) and molecular genetic findings, the latter characterized by mutually exclusive KIT or plateletderived growth factor receptor- $\alpha$ (PDGFRA) muta-

Correspondence: Dr CE Bacchi, MD, Consultoria em Patologia, Rua Major Leonidas Cardoso, 739, Botucatu, Sao Paulo, 18602-010, Brazil.

E-mail: bacchi@consultoriapatologia.com.br

Received 17 April 2007; revised 12 June 2007; accepted 18 June 2007; published online 20 July 2007 tions. ${ }^{1,2}$ The KIT and PDGFRA genes encode for similarly named transmembrane tyrosine kinase receptors that are involved in the development and maintenance of several cells. Activating (gain-offunction) mutations of KIT or PDGFRA permit the phosphorylation of the receptor tyrosine kinases, with activation of intracellular downstream effectors, resulting in increased cellular proliferation and decreased apoptosis, ultimately leading to neoplasia. $^{3-6}$ The development of a KIT and PDGFRA tyrosine kinase inhibitor called STI571 or imatinib mesylate (Gleevec, Novartis Pharma, Basel, Switzerland $)^{7}$ has brought new perspectives in GIST treatment by reducing KIT receptor tyrosine kinase activity.

The epidermal growth factor receptor (EGFR, HER-1/ErbB-1) is a tyrosine kinase receptor of the ErbB family also involved in intracellular signaling 
pathways that regulate key cellular processes such as proliferation, survival, adhesion, migration and differentiation. EGFR has been the subject of intense investigation in view of its involvement in some types of cancer such as non-small-cell lung carcinoma, being a potential molecular target of therapy with kinase inhibitors. ${ }^{8-10}$ However, very few reports have been published so far regarding the role of EGFR in GIST ${ }^{11-13}$ and further investigation was necessary to define if EGFR could be an additional molecular target in GIST treatment.

This study was designed to provide additional information about the relationship between GIST and EGFR, and to help define potential therapies for GIST by investigating EGFR protein expression and EGFR gene amplification.

\section{Materials and methods}

\section{Case Material and Clinical Data}

The study group included 82 consecutive cases of GIST received in consultation between June 2003 and May 2004 at Consultoria em Patologia, a reference consultation service in anatomic pathology located in Botucatu, Sao Paulo State, Brazil. Both GI tract and extra-GI tract GIST cases were included. All cases had morphological features of GIST. Clinical data including gender, age at diagnosis, tumor location and tumor size were obtained from the referring pathologists/oncologists and/or pathology reports.

\section{Analysis of Histologic Parameters}

Available hematoxilin- and eosin-stained slides were reviewed in each case. Cell morphology (spindle, epithelioid and mixed spindle/epithelioid) was recorded.

\section{Tissue Microarray Construction}

A tissue microarray block was constructed using a tissue arrayer (Beecher Instruments, Sun Prairie, WI, USA). Each case was represented by three tumor cores of $0.6 \mathrm{~mm}$ that were taken from the original paraffin blocks. Serial sections of $3 \mu \mathrm{m}$ were cut from the tissue array block and used for immunohistochemical and fluorescence in situ hybridization (FISH) analyses. Proper positive controls cores were also included in the array block to provide adequacy of the antibodies used in the immunohistochemical study.

\section{Immunohistochemistry}

Polyclonal antibody against CD117 (c-kit, 1:200; DAKO, Carpinteria, CA, USA) and monoclonal antibodies against EGFR (clone 31G7, 1:50; Zymed,
San Francisco, CA, USA) and CD34 (clone My10, 1:400; Becton Dickinson Biosciences, Mountain View, CA, USA) were used for immunohistochemical analysis. Heat-induced (CD117 and CD34) and enzymatic (protease XXVI for EGFR) antigen retrieval was employed. Novolink polymer (Novocastra, Newcastle Upon Tyne, UK) was the detection system, and diaminobenzidine was the chromogen.

Immunostains for CD117 and CD34 were interpreted as positive or negative. EGFR was scored according to the intensity of the immunostaining as 0 (negative), 1 (positive, weak), 2 (positive, moderate) or 3 (positive, strong). EGFR was considered positive $(1,2$ or 3$)$ if staining was mainly membranous in at least $10 \%$ of the tumor cells.

\section{Fluorescence In Situ Hybridization}

FISH was used to estimate the copy number of the EGFR gene in each case using a 3- $\mu$ m-thick tissue section of the array block. Dual color EGFR FISH was performed with the SpectrumOrange LSI EGFR probe specific for the EGFR locus (7p12) and the SpectrumGreen CEP7 probe specific for chromosome 7 centromere (7p11.1-q11.1), according to the manufacturer's instructions (Vysis, Abbott AG, Baar, Switzerland) and as previously described. ${ }^{14}$ The quantification of EGFR gene copy number was performed using a Zeiss Axio Imager M1 fluorescence microscope (Carl Zeiss AG, Germany) with appropriate filters (Chroma Technology GmbH, Fuerstenfeldbruck, Germany) and the assistance of Isis FISH Imaging software (Metasystems, Altlussheim, Germany).

\section{Results}

\section{GIST Clinical and Morphological Characterization}

There were 48 males and 34 females and the mean age was 58 years (23-85 years). The tumors were located in the stomach (33\%), small intestine (39\%), large intestine $(5 \%)$, mesentery $(5 \%)$, pancreas/ peripancreatic tissue $(4 \%)$, liver $(4 \%)$, abdominal cavity $(4 \%)$ and retroperitoneum $(1 \%)$. Five cases had unknown location. The tumors ranged in size from 2 to $31 \mathrm{~cm}$ (mean, $11 \mathrm{~cm}$ ). The cell types were pure spindle $(75 \%)$, pure epithelioid $(10 \%)$ and mixed spindle/epithelioid (15\%).

\section{GIST Immunohistochemical Characterization}

Immunohistochemistry revealed that CD117 was expressed in 79 out of 82 tumors (96\%). CD34 expression was observed in 46 out of 81 GISTs (57\%). Variable EGFR protein immunohistochemical overexpression was detected in $96 \%(n=76)$ of scorable GISTs $(n=79)$. Only three $(4 \%)$ tumors were scored 0 . Ten tumors $(12 \%)$ were scored 1 , 

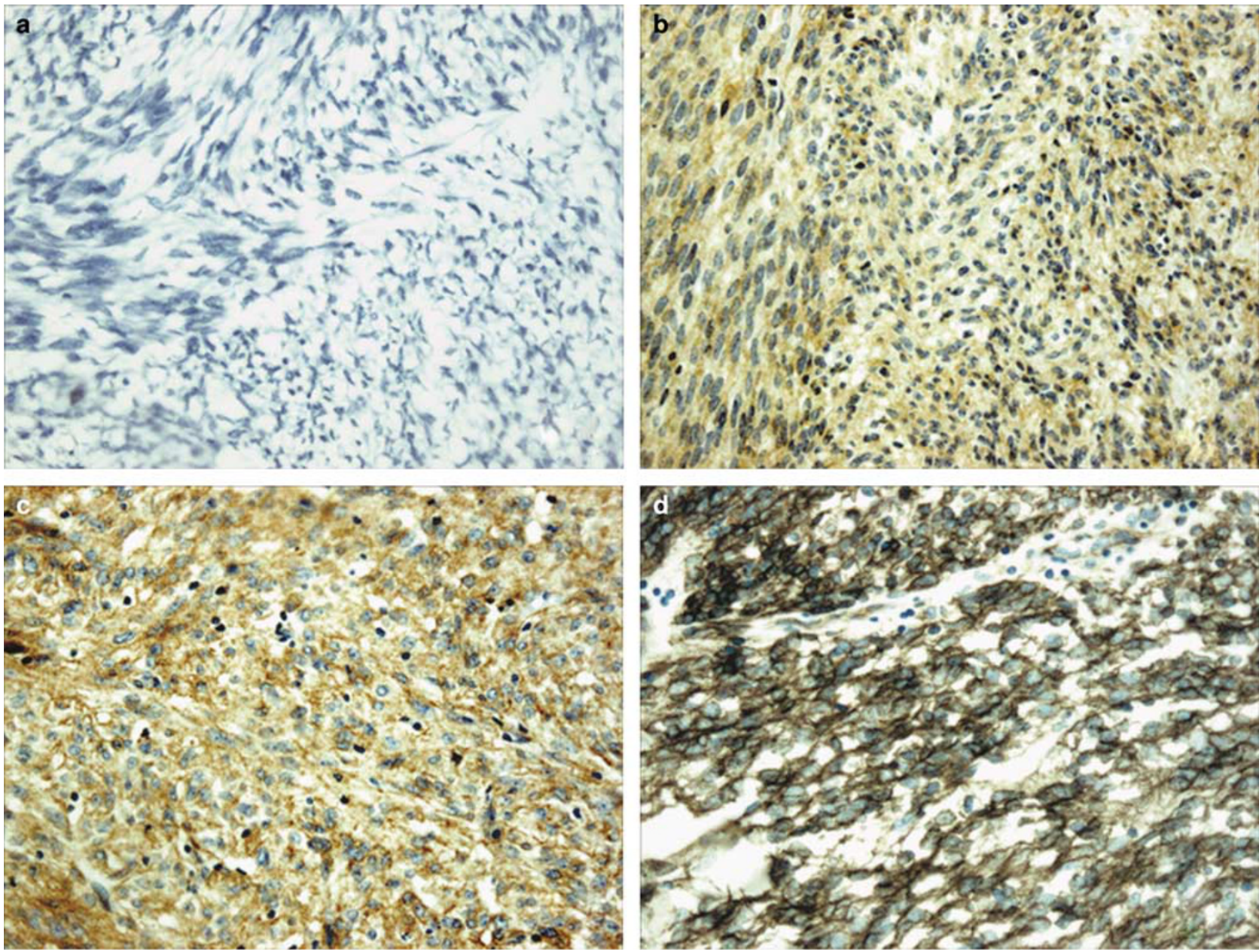

Figure 1 EGFR protein expression in GIST. (a) GIST score 0-no EGFR expression. (b) GIST score 1—weak EGFR expression. (c) GIST score 2-moderate EGFR expression. (d) GIST score 3-strong EGFR expression.

$21(27 \%)$ were scored 2 and $45(57 \%)$ were scored 3 (Figure 1).

\section{EGFR Gene Copy Number Quantification}

Seventy-five GISTs had tumor tissue cores represented in the section submitted to FISH and countable fluorescence signals. All 75 cases showed two orange (EGFR gene) and two green (chromosome 7 centromere) fluorescence signals, with a signal ratio EGFR gene/CEP 7 equal to 1, which means that all cases had no amplification of the EGFR gene (Figure 2). EGFR gene amplification is defined as a signal ratio EGFR gene/CEP 7 equal to or higher than 2.

\section{Discussion}

EGFR (HER-1) is a receptor tyrosine kinase that plays a key role in the regulation of essential normal cellular processes and in the pathophysiology of hyperproliferative diseases such as cancer. EGFR

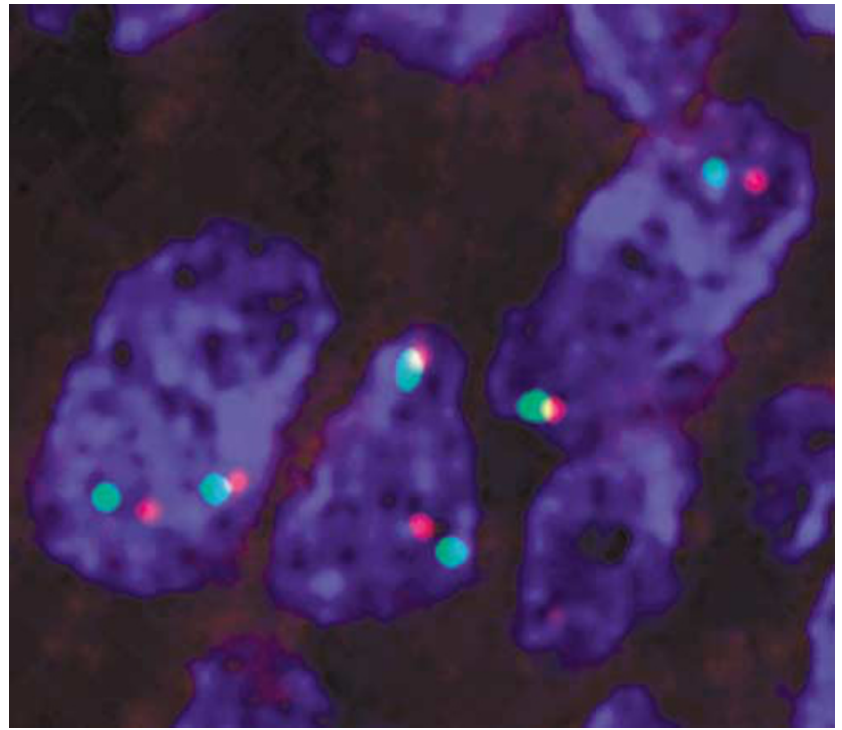

Figure 2 Fluorescence in situ hybridization demonstrates the presence of two orange signals ( $E G F R$ gene) and two green signals (chromosome 7 centromere) per cell. No amplification of EGFR gene can be observed. 
is known to be essential for mediation of both proliferative and survival signals to cells. Activation of the EGFR signaling pathway has been linked with increased cell proliferation, angiogenesis, metastasis and decreased apoptosis.

The literature has presented many reports that demonstrate the link between EGFR and some types of cancer, ${ }^{15-20}$ which are generally associated with poor clinical outcome. Small molecules that inhibit the tyrosine kinase domain of EGFR have become critical new weapons in the treatment of some tumors, including non-small-cell lung carcinomas, ${ }^{21}$ and they include gefitinib (Iressa, Astra Zeneca) and erlotinib (Tarceva, OSI Pharmaceuticals).

The role of EGFR has been studied in several types of human sarcomas, ${ }^{22-30}$ mainly in synovial sarcomas. ${ }^{14,23,29}$ On the other hand, very few reports about the relationship between GIST and EGFR have been published so far. ${ }^{11-13}$

Cai et $a l^{11}$ studied the expression of transforming growth factor- $\alpha$ (TGF- $\alpha$ ) and two EGFR proteins (HER-1 and HER-2) in GISTs of the stomach and small intestine using standard immunostaining techniques in paraffin-embedded sections. Most GISTs expressed TGF- $\alpha$, and a few expressed HER1 , suggesting that a TGF- $\alpha$ /EGFR autocrine loop was present in GIST and that TGF- $\alpha$ could promote proliferation of GIST tumor cells through its interaction with HER-1 in at least some GISTs.

Lanzafame et $a l^{12}$ reported a GIST case occurring during pregnancy with immunohistochemical staining for EGFR, indicating that the expression of EGFR could provide pertinent biological information required to determine adequate therapeutic regimens. Interestingly, Yoo et $a l^{13}$ analyzed the EGFR gene in 60 GISTs for the detection of somatic mutations by using the polymerase chain reaction, the single-strand conformation polymorphism (SSCP) and DNA sequencing of exons 18, 19 and 21 encoding the kinase domain. The SSCP analysis revealed no evidence of EGFR mutations in those exons of the EGFR gene. The data indicated that the EGFR gene might not be mutated in human GISTs and suggested that therapies targeting the mutated EGFR gene products might not be useful in the treatment of GISTs.

On the other hand, Yang et al ${ }^{31}$ explored the effect of ZD6474 (Zactima, AstraZeneca, Macclesfield, UK), an orally available small-molecule inhibitor of vascular endothelial growth factor receptor-2 and EGFR tyrosine kinases, in GIST-T1 cells. ZD6474 induced growth arrest and apoptosis of GIST-T1 cells in association with blockade of KIT and its downstream effectors.

Considering some conflicting findings, additional investigation was mandatory. In the present study, we found that most GISTs had immunohistochemical overexpression of EGFR protein, but none of the cases studied by FISH had gene amplification, even though Tornillo et $a l^{32}$ found amplification for EGFR in $5.3 \%$ of GISTs. Results regarding EGFR over- expression in the absence of gene amplification were also observed by Bode et $a l^{14}$ in synovial sarcomas. They studied 13 synovial sarcomas that exhibited strong diffuse or focal EGFR expression with no EGFR gene amplifications, but several point mutations were detected in exons 18-21 of two synovial sarcomas. They stated that the existence of mutations in the tyrosine kinase domain of the EGFR gene could make a small subset of synovial sarcomas suitable for treatment with EGFR inhibitors. Other authors ${ }^{33,34}$ observed similar findings in gliomas and suggested that the expression of EGFR protein could be enhanced by mechanisms other than simple alteration in EGFR gene copy number. Several mechanisms have been proposed to explain EGFR protein overexpression, including EGFR gene activating mutations, increased EGFR transcription or translation, decreased protein destruction and overexpression of receptor ligands. ${ }^{35}$ Considering that the mechanisms of EGFR protein overexpression are not well understood and the possibility that anti-EGFR therapy may be beneficial for patients with GIST that overexpresses EGFR protein, further studies are necessary.

In summary, we found that EGFR protein was overexpressed in $96 \%$ of GISTs included in this study. Such result could make EGFR a possible molecular target of therapy, although EGFR gene amplification was not detected.

\section{Acknowledgement}

We acknowledge the outstanding service of Consultoria em Patologia staff for skillful technical assistance.

\section{Disclosure/conflict of interest}

No conflict of interest to declare.

\section{References}

1 Rubin BP. Gastrointestinal stromal tumours: an update. Histopathology 2006;48:83-96.

2 Miettinen M, Lasota J. Gastrointestinal stromal tumours. Review on morphology, molecular pathology, prognosis, and differential diagnosis. Arch Pathol Lab Med 2006;130:1466-1478.

3 Hirota S, Isozaki K, Moriyama Y, et al. Gain-of-function mutations of c-kit in human gastrointestinal stromal tumors. Science 1998;279:577-580.

4 Corless CL, Fletcher JA, Heinrich MC. Biology of gastrointestinal stromal tumors. J Clin Oncol 2004;22: 3813-3825.

5 Corless CL, McGreevey L, Haley A, Town A, Heinrich MC. KIT mutations are common in incidental gastrointestinal stromal tumors one centimeter or less in size. Am J Pathol 2002;160:1567-1572. 
6 Heinrich MC, Corless CL, Duensing A, et al. PDGFRA activating mutations in gastrointestinal stromal tumors. Science 2003;299:708-710.

7 Savage DG, Antman KH. Imatinib mesylate-a new oral targeted therapy. N Engl J Med 2002;346:683-693.

8 Lynch TJ, Bell DW, Sordella R, et al. Activating mutations in the epidermal growth factor receptor underlying responsiveness of non-small-cell lung cancer to gefitinib. N Engl J Med 2004;350:2129-2139.

9 Takano T, Ohe Y, Sakamoto H, et al. Epidermal growth factor receptor gene mutations and increased copy numbers predict gefitinib sensitivity in patients with recurrent non-small-cell lung cancer. J Clin Oncol 2005;23:6829-6837.

10 Hirsch FR, Varella-Garcia M, Bunn Jr PA, et al. Epidermal growth factor receptor in non-small-cell lung carcinomas: correlation between gene copy number and protein expression and impact on prognosis. J Clin Oncol 2003;21:3798-3807.

11 Cai YC, Jiang Z, Vittimberga F, et al. Expression of transforming growth factor-alpha and epidermal growth factor receptor in gastrointestinal stromal tumours. Virchows Arch 1999;435:112-115.

12 Lanzafame S, Minutolo V, Caltabiano R, et al. About a case of GIST occurring during pregnancy with immunohistochemical expression of epidermal growth factor receptor and progesterone receptor. Pathol Res Pract 2006;202:119-123.

13 Yoo NJ, Lee JW, Soung YH, et al. Mutational analysis of the epidermal growth factor receptor gene in gastrointestinal stromal tumors. J Korean Gastric Cancer Assoc 2004;4:268-271.

14 Bode B, Frigerio S, Behnke S, et al. Mutations in the tyrosine kinase domain of the EGFR gene are rare in synovial sarcoma. Mod Pathol 2006;19:541-547.

15 Chung CH, Ely K, McGavran L, et al. Increased epidermal growth factor receptor gene copy number is associated with poor prognosis in head and neck squamous cell carcinomas. J Clin Oncol 2006;24:4170-4176.

16 Stadlmann S, Gueth U, Reiser U, et al. Epithelial growth factor receptor status in primary and recurrent ovarian cancer. Mod Pathol 2006;19:607-610.

17 Layfield LJ, Willmore C, Tripp S, et al. Epidermal growth factor receptor gene amplification and protein expression in glioblastoma multiforme: prognostic significance and relationship to other prognostic factors. Appl Immunohistochem Mol Morphol 2006;14: 91-96.

18 Kersting C, Kuijper A, Schmidt H, et al. Amplifications of the epidermal growth factor receptor gene (EGFR) are common in phyllodes tumors of the breast and are associated with tumor progression. Lab Invest 2006;86:54-61.

19 Hanawa M, Suzuki S, Dobashi Y, et al. EGFR protein overexpression and gene amplification in squamous cell carcinomas of the esophagus. Int J Cancer 2006;118: 1173-1180.

20 Sauter G, Haley J, Chew K, et al. Epidermal-growthfactor-receptor expression is associated with rapid tumor proliferation in bladder cancer. Int J Cancer 1994;57:508-514.
21 Edelman MJ. An update on the role of epidermal growth factor receptor inhibitors in non-small cell lung cancer. Semin Oncol 2005;32:S3-S8.

22 Dobashi Y, Takei N, Suzuki S, et al. Aberration of epidermal growth factor receptor expression in bone and soft-tissue tumors: protein overexpression, gene amplification and activation of downstream molecules. Mod Pathol 2004;17:1497-1505.

23 Thomas DG, Giordano TJ, Sanders D, et al. Expression of receptor tyrosine kinases epidermal growth factor receptor and HER-2/neu in synovial sarcoma. Cancer 2005;103:830-838.

24 Ganti R, Skapek SX, Zhang J, et al. Expression and genomic status of EGFR and ErbB-2 in alveolar and embryonal rhabdomyosarcoma. Mod Pathol 2006;19: 1213-1220.

25 Yang JL, Hannan MT, Russell PJ, et al. Expression of HER1/EGFR protein in human soft tissue sarcomas. Eur J Surg Oncol 2006;32:466-468.

26 Sato O, Wada T, Kawai A, et al. Expression of epidermal growth factor receptor, ERBB2 and KIT in adult soft tissue sarcomas: a clinicopathologic study of 281 cases. Cancer 2005;103:1881-1890.

27 Moinfar F, Gogg-Kamerer M, Sommersacher A, et al. Endometrial stromal sarcomas frequently express epidermal growth factor receptor (EGFR, HER-1): potential basis for a new therapeutic approach. Am J Surg Pathol 2005;29:485-489.

28 Hughes DP, Thomas DG, Giordano TJ, Baker LH, McDonagh KT. Cell surface expression of epidermal growth factor receptor and Her-2 with nuclear expression of Her-4 in primary osteosarcoma. Cancer Res 2004;64:2047-2053.

29 Nielsen TO, Hsu FD, O’Connell JX, et al. Tissue microarray validation of epidermal growth factor receptor and SALL2 in synovial sarcoma with comparison to tumors of similar histology. Am J Pathol 2003;163:1449-1456.

30 Gusterson B, Cowley G, McIlhinney J, et al. Evidence for increased epidermal growth factor receptors in human sarcomas. Int J Cancer 1985;36:689-693.

31 Yang Y, Ikezoe T, Nishioka C, et al. ZD6474 induces growth arrest and apoptosis of GIST-T1 cells, which is enhanced by concomitant use of sunitinib. Cancer Sci 2006;97:1404-1409.

32 Tornillo L, Duchini G, Carafa V, et al. Patterns of gene amplification in gastrointestinal stromal tumors (GIST). Lab Invest 2005;85:921-931.

33 Bredel M, Pollack IF, Hamilton RL, et al. Epidermal growth factor receptor expression and gene amplification in high-grade non-brainstem gliomas of childhood. Clin Cancer Res 1999;5:1786-1792.

34 Waha A, Baumann A, Wolf HK, et al. Lack of prognostic relevance of alterations in the epidermal growth factor receptor-transforming growth factoralpha pathway in human astrocytic gliomas. J Neurosurg 1996;85:634-641.

35 Wang X, Zhang S, MacLennan GT, et al. Epidermal growth factor receptor protein expression and gene amplification in small cell carcinoma of the urinary bladder. Clin Cancer Res 2007;13:953-957. 